Case Report

\title{
Apical surgery with calcium hydroxide capping of the exposed dentine: a case report
}

\author{
Janir A. Soares ${ }^{1)}$, Frank F. Silveira ${ }^{2,3)}$ and Eduardo Nunes ${ }^{2)}$ \\ ${ }^{1)}$ Federal University of the Valleys of Jequitinhonha and Mucuri, Diamantina, MG, Brazil \\ ${ }^{2)}$ Department of Endodontics, Catholic University, Belo Horizonte, MG, Brazil \\ ${ }^{3)}$ Itaúna University, MG, Brazil
}

(Received 27 June and accepted 26 December 2006)

\begin{abstract}
Among a variety of biomaterials that have been reported to be ideal for dental repair, calcium hydroxide has been shown to have excellent long-term biocompatibility in the pulp and periapical areas. Here we report an alternative method employing calcium hydroxide for periapical surgery in a patient who developed internal apical resorption after traumatic injury, which negatively affected the quality of the cleaning, shaping and filling of the root canal. Obturation of the root canal as far as the middle third was followed by apicoectomy and ultrasonic retropreparation, and then retrograde root filling with resin cement sealer (Sealer 26) and zinc oxide powder. Calcium hydroxide paste was applied over the exposed dentinal surface, forming a barrier over the root apex. Radiographic follow-up after 24 months showed absence of apical resorption and complete periapical bone repair associated with a continuous apical lamina dura. (J. Oral Sci. 49, 79-83, 2007)
\end{abstract}

Keywords: apicoectomy; calcium hydroxide; retrofilling; tooth resorption.

\section{Introduction}

Depending on its severity, injury to the oral cavity can involve all dental tissues (1). In relation to the pulp tissue, calcification, internal resorption and/or pulp necrosis are

Correspondence to Dr. Frank Ferreira Silveira, Department of Endodontics, Catholic University, Pç Dr Augusto Gonçalves 146 sala 510, Centro Itaúna, MG, CEP: 35.680.054, Brazil Tel: +55-37-32421398

Fax: +55-31-33194415

E-mail: frankfoui@uol.com.br potential sequelae of dental traumatic injuries (2). The evolution of internal resorption necessarily requires the maintenance of a blood supply, allowing odontoclast cells to be active. The pathogenic process begins with inflammation, which is discrete and focal, with liberation of chemical mediators that cause local damage to pulp parenchyma, destroying the odontoblast layer and predentin, followed by exposure of mineralized dentine $(1,3)$. Stem cells from the bone medulla circulating in the blood come into contact with the altered or unprotected dentin and differentiate into dentinoclasts, forming multinuclear giant cells that resorb the organic and inorganic portion, creating microcavities which advance irregularly and asymptomatically through the root structure, finally reaching the surface of the periodontal ligament $(2,4)$.

Topographically, internal resorption may begin in any segment of the pulp chamber, and radiographically its development presents an oval or circular shape, which is well defined and homogeneous. In the case of the root, a uniform and usually symmetrical chamber is formed along the path of the root canal $(1,2)$. Internal root resorption, while restricted to the endodontic space, can only be resolved through adequate cleaning, shaping and obturation of the root canal $(4,5)$. However, when there is periodontal involvement, complementary periapical surgery becomes necessary $(4,6)$.

For many years silver amalgam was the most commonly used retrofilling material for periapical surgery. Due to questions raised about marginal infiltration and biocompatibility, however, many other biomaterials, such as MTA (Mineral Trioxide Aggregate), have been used, $(7,9)$. Here we describe a clinical case that illustrates the use of an alternative retrofilling material, as well as a recently developed method for treatment of the root surface exposed by apicoectomy. 


\section{Case Report}

Diagnosis, planning and preliminary endodontic treatment

A 17-year-old patient presented at the endodontic clinic of the Federal University of the Valleys of Jequitinhonha and Mucuri, with a history of trauma to the upper anterior teeth, which had occurred six months previously as a result of a bicycle accident. The trauma included avulsion of tooth \#21. The patient received immediate professional help in which the tooth was repositioned and retained by a semi-rigid splint. Clinical examination revealed mild tooth discoloration. Among the upper anterior teeth, only tooth \#21 was not responsive to pulp sensitivity tests, including the cold test (Endo-Ice, The Hygienic Corp., Ohio, USA) and an electric pulp tester (Vitapulp, Pelton \& Crane Co., North Carolina, USA). Periapical radiography (Fig. 1) showed changes in the outline of the root canal in the apical region, from the apical foramen extending approximately $4 \mathrm{~mm}$, with the greatest diameter near the foramen. Based on the history of trauma, pulp sensitivity tests complemented by radiographic interpretation, a diagnosis of internal apical resorption of traumatic origin was made. Taking into account the location and oval-shaped

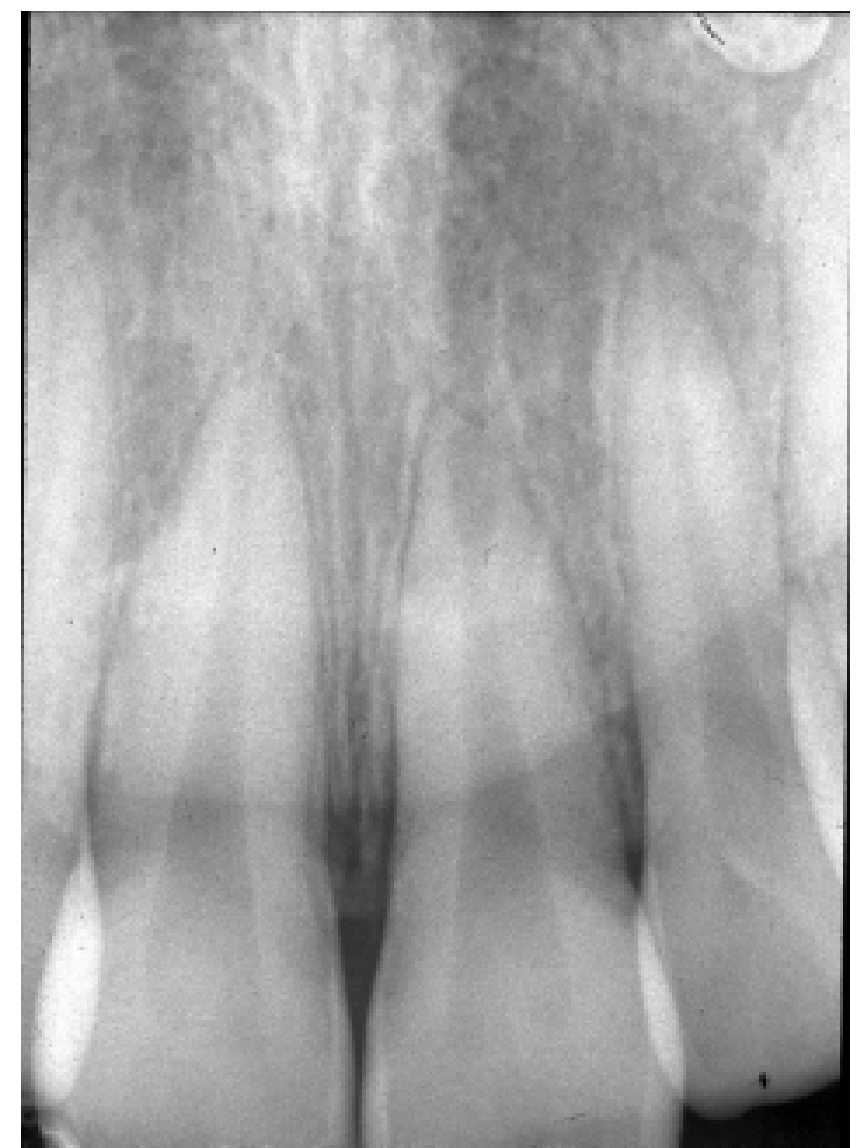

Fig. 1 Apical third of the root canal showing internal resorption. enlargement of the resorptive area, the first step of treatment planning was root canal treatment followed by periapical surgery, including apicoectomy with retropreparation followed by retrograde filling. This protocol was approved by the institutional ethics committee and free and informed consent was obtained from the patient. An access cavity preparation was created exposing the necrotic pulp tissue. Root canal preparation was undertaken up to approximately $6 \mathrm{~mm}$ short of the radiographic apex, given the impossibility of creating a satisfactory apical stop to engage the principal gutta-percha cone. Thus progressive cleaning and shaping of the root canal up to a Kerr \#90 file was done, followed by step back preparation with the use of Gates-Glidden drills \#4, 5 and 6 , and irrigation with $1 \%$ sodium hypochlorite. In this segment of the root canal there was pulp hemorrhage. After removal of the smear layer, root canal sealing was done using gutta-percha cones plasticized with heat, rolled and molded in the root canal, associated with cement Sealer 26 (Dentsply Industria e Comércio Ltd, Rio de Janeiro, Brazil), using the thermomechanical compaction technique, followed by coronal sealing (Fig. 2).

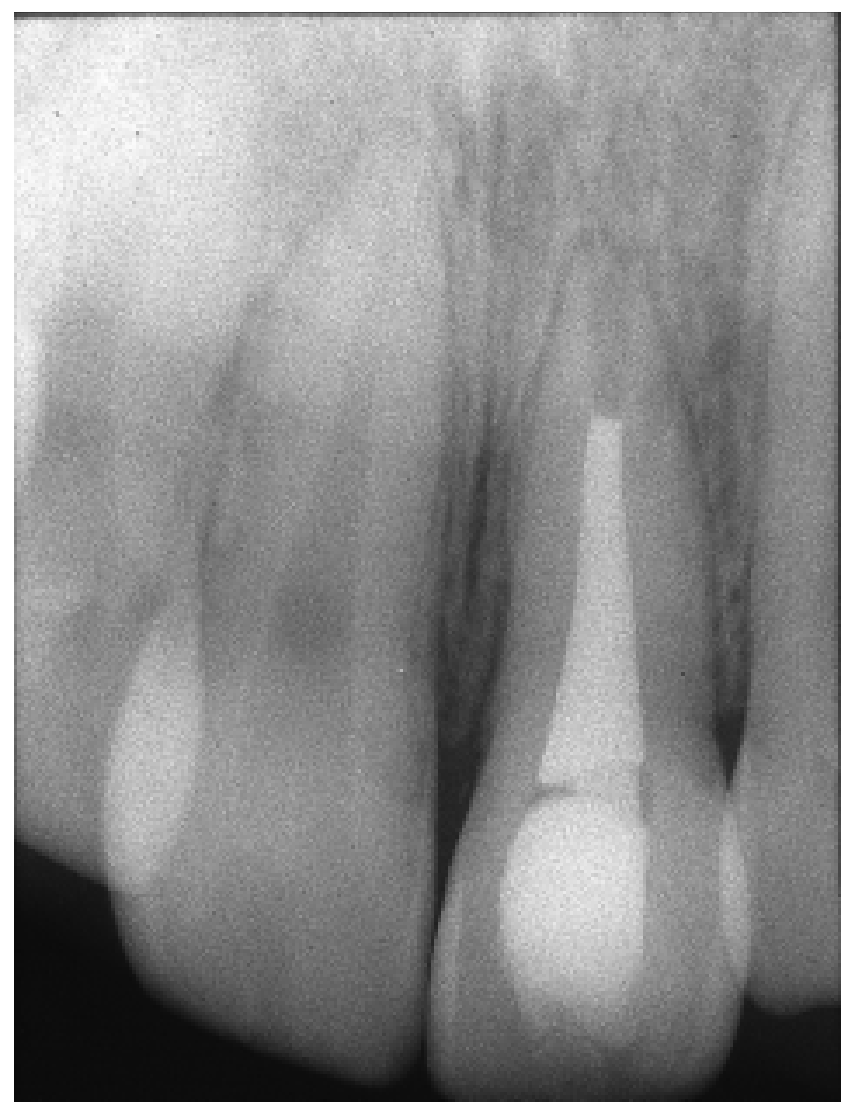

Fig. 2 Root canal filling. 


\section{Conclusion of endodontic treatment and periapical surgery}

A Wasmund-type mucogingival incision was made under local anesthesia, a full flap was retracted, and bone removed to gain access to the apical third of the root. The resection involved the apical $3 \mathrm{~mm}$ of the root, using a highspeed diamond bur \#3205 (KG Sorensen, São Paulo, Brazil), followed by finishing with a diamond bur \#3195FF (KGS) and irrigation with sterile saline. Retropreparation of the remaining apex was done using a Kerr \#35 file, previously angulated and coupled to an ultrasonic unit (Profi II-Dabi-Atlante, São Paulo, Brazil) at medium/low power, for approximately $30 \mathrm{sec}$, with irrigation, followed by irrigation of the surgical field with $0.12 \%$ chlorhexidine digluconate. After drying the retro-cavity with small paper points, retrofilling was undertaken with a resin endodontic cement containing calcium hydroxide (Sealer 26, Dentsply Indústria e Comércio Ltd, Petrópolis, Brazil) thickened with zinc oxide powder, and mixing to obtain a clay-like consistency. The material was compacted incrementally with a dentin excavator, and underfilled to leave a space of aproximately $1 \mathrm{~mm}$, which was then filled with a paste of calcium hydroxide mixed with saline solution a rate of $0.9 \mathrm{~g} / \mathrm{ml}$, resulting in a toothpaste-like consistency. The dentin surface exposed by the resection was covered with this paste, using an excavator, forming a "calcium hydroxide apical barrier' with a thickness of approximately $1 \mathrm{~mm}$ (Fig. 3). Postoperative cold compresses were prescribed with systemic analgesia and anti-inflammatory medication based on ibuprofen. Follow-up at 24 months showed that the patient was clinically asymptomatic, with no sign of dentine resorption and complete periapical bony repair associated with the formation of a periapical lamina dura (Fig. 4).

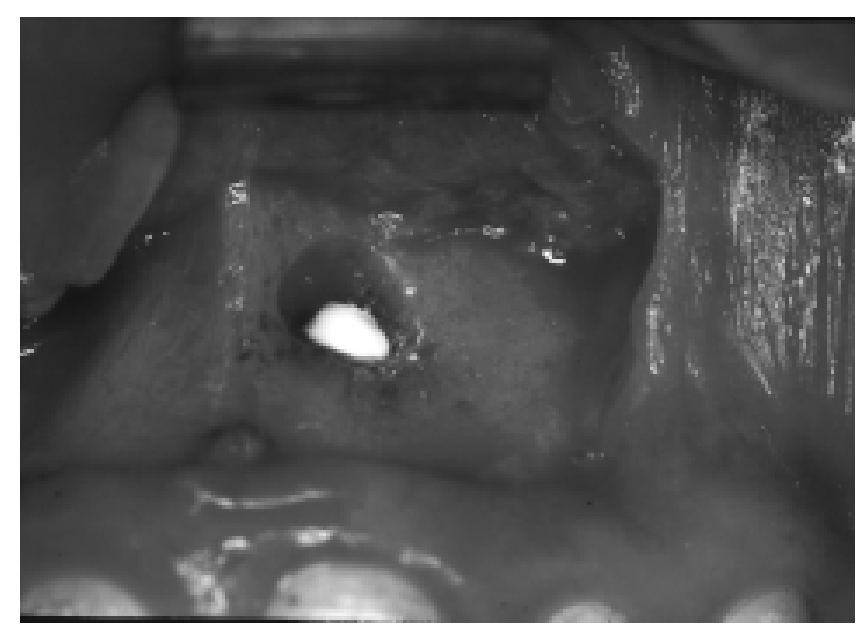

Fig. 3 Calcium hydroxide apical barrier on exposed dentin after root resection.

\section{Discussion}

Undoubtedly, root canal treatment is the best solution for common pulpal and periapical diseases. However, there are specific situations in which periapical surgery makes an important contribution to endodontic treatment. Thus, when the resorption is only internal, root canal treatment with the use of $5.25 \%$ sodium hypochlorite solution during cleaning and shaping, followed by immediate filling, can effectively resolve the pathological condition $(4,6,10,11)$. Some authors have also recommended the use of calcium hydroxide paste after instrumentation (12). In such cases, the resorption is confined to the pulp cavity. In other situations, such as root perforations caused by instruments, the use of calcium hydroxide would be indicated in order to seal the communication established between the pulp cavity and the periodontal ligament. If this is successful, root canal filling can be performed, obviating the need for periodontal surgery $(7,9)$.

However, when there is communication between the pulp cavity and the periodontal space due to internal resorption, the use of calcium hydroxide before root canal filling

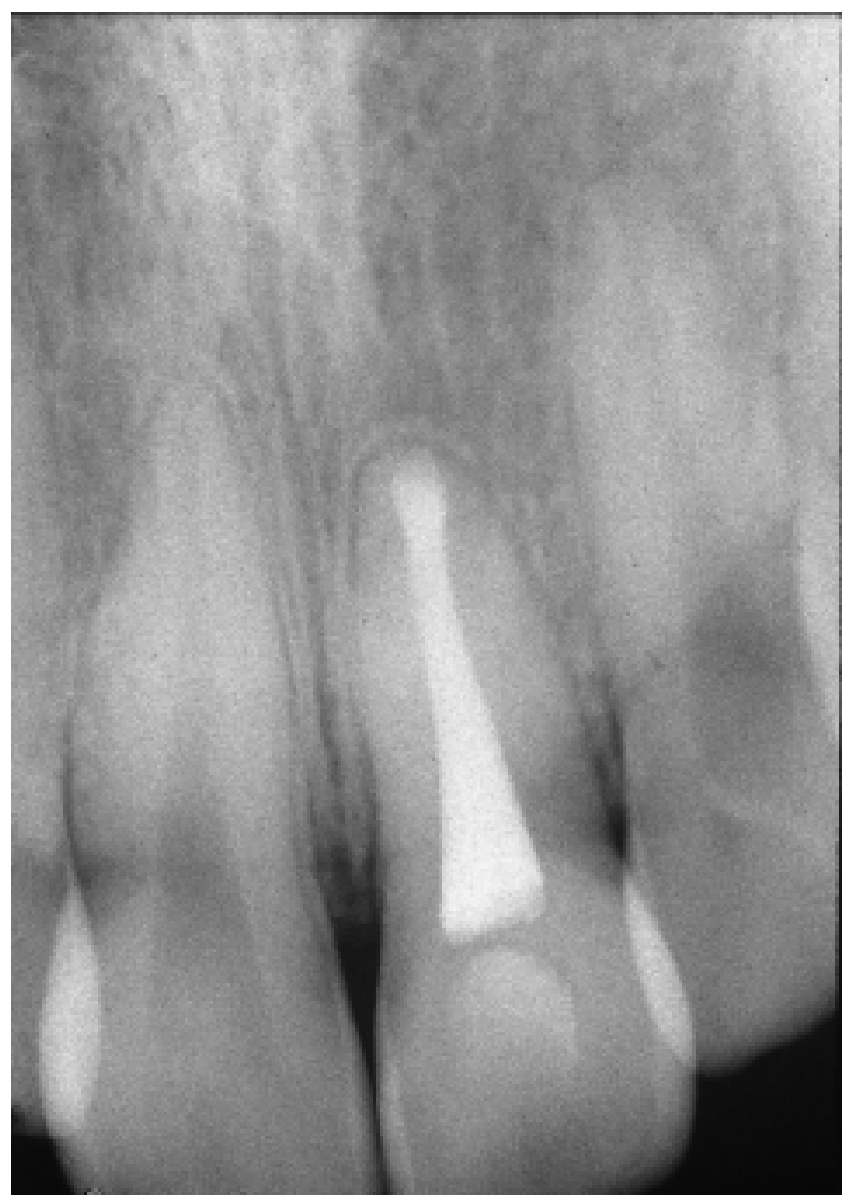

Fig. 4 Follow-up after 24 months, showing complete periapical repair with formation of a continuous lamina dura. 
would be meaningless, since the resorptions sites would be full of osteoclasts that need to be removed surgically (12). In the present case, resorption had caused significant irregularity in the apical segment of the root canal, and also extended through the apical foramina. Such a condition compromises the quality of orthograde cleaning, shaping and filling, with possible maintaining of apical resorption after treatment, the reason why it has been made the periapical surgery with retropreparation and retrofilling.

Periapical surgery is successful in $25.0-99.0 \%$ of cases, and success is influenced by many factors including the tooth involved, surgical procedure, complex anatomy of the root canal system, quality of root canal filling, apical repair and the length of follow-up $(5,10,13)$. In relation to retrofilling materials, their marginal sealing capacity and biocompatibility are the aspects that have been studied most commonly. Such studies have questioned the effectiveness of silver amalgam, since other biomaterials such as composite adhesives/resins, glass-ionomer cements, composite resin-reinforced glass-ionomer, EBA aluminum and MTA cement have shown superior performance $(7,9,14)$.

Due to the irregular oval-shaped area of internal resorption, ultrasonic retropreparation represents the safest and most efficient way to clean and shape the apical segment of the root canal (15). In the present case, retrofilling was undertaken with Sealer 26, a resin cement derived from $\mathrm{AH} 26$, which has been shown to have good apical sealing properties (16). In addition, when this cement is thickened with zinc oxide, it has low solubility $(6,17)$, improving its application for retropreparation (18), and is far less expensive than MTA (18).

Application of calcium hydroxide to apicoectomized dentinal surfaces has mostly been done for reparative purposes, since dentin resorption frequently develops at sites of apical resection (19), possibly due to (1) the specific propensity of dentine to attract clastic cells as a result of its lack of natural protection by pre-dentine and cement, (2) biochemical alteration of collagen as a result of heating during apical resection, (3) irregularities generated by cutting instruments, and (4) presence of microorganisms in apical dentinal tubules. It can also be speculated that apical dentine resorption occurs as an adaptive response of the apex to occlusal forces concentrating at this region after accomplishment of angulated apical resection, as observed in photoelastic models (20). Apical resection perpendicular to the root axis, followed by edge regularization, was performed to reduce this occurrence.

Although remodeling due to dental resorption may be inevitable, procedures that can minimize these processes should be used, starting with a regular and perpendicular cut along the long axis of the root, followed by rounding and smoothing of the angles (20). This angle of cut exposes the minimum number of dentinal tubules and reduces interchange between the apex and the root canal, resulting in less infiltration of the dentin and the wall/filling interface of the root canal $(13,21)$.

The type of dentin surface treatment also influences the magnitude of superficial resorption, and calcium hydroxide tends to reduce this process, since $\mathrm{Ca}^{++}$and $\mathrm{OH}^{-}$play a role in various cellular mechanisms and affect molecules that induce tissue repair, for example: 1) control of inflammation by hydroscopic action, formation of calcium protein bridges and inhibition of phospholipase enzymes, 2) neutralization of acid products of osteoclasts (acid hydrolases and lactic acid), 3) induction of mineralization (activation of alkaline phosphatase and calcium-dependant ATPases), and 4) stimulation of cellular differentiation, besides its proved antibacterial action (22-24). Consequently, it is speculated that its action on dentin and tissues surrounding the dental apex establishes favorable conditions for adhesion, proliferation and differentiation of mineralized tissue-repairing cells, allowing insertion of collagen fibers and reorganization of the apical periodontal ligament.

The use of calcium hydroxide to form a small barrier on the surface of the resected root was first advocated by two biological endodontists, Holland \& Bernabé (25). This type of treatment gives satisfactory clinical and radiographic results, and histologically is associated with a lower incidence of root resorption of the apicoectomized dentin, allied with greater efficiency of biological sealing of the foramen, either partial or complete, by mineralized tissue (25).

On the other hand, a comparison could be made between the calcium hydroxide barrier and small apical extrusions of this paste, which have shown a satisfactory tissue repair response in dogs with induced apical lesions (26). Such histological aspects may be correlated with complete bone repair and the presence of an apical lamina dura, as observed in a clinical case (18), suggesting that this treatment shows considerable promise for this type of apicoectomized root surface.

\section{References}

1. Trope M, Chivian N (1994) Traumatic injuries. In Pathways of the pulp, 6th ed, Cohen S, Burns RC eds, Mosby, St Louis, 16, 436-485

2. Robertson A, Andreasen FM, Bergenholtz G, Andreasen JO, Norén JG (1996) Incidence of pulp necrosis subsequent to pulp canal obliteration from 
trauma of permanent incisors. J Endod 22, 557-560

3. Stanley HR, Weisman MI, Michanowicz AE, Bellizzi R (1978) Ischemic infarction of the pulp: sequencial degenerative changes of the pulp after traumatic injury. J Endod 4, 325-335

4. Soares JA, César CAS, Maia Filho EM, Bonetti Filho I (1999) Bioligical perspectives of endodontic treatment of traumatized teeth. A clinic case report. J Bras Clin Estét Odontol 3, 74-77 (in Portuguese)

5. Molven O, Halse A, Grung B (1991) Surgical management of endodontic failures: indications and treatment results. Int Dent J 41, 33-42

6. Soares JA, Tanomaru Filho M, César CAS, Borges EF, Pimentel RF (1999) Endodontic surgery with simultaneous root canal filling. Description of the technic and case report. J Bras Clin Estét Odontol 3, 74-77 (in Portuguese)

7. Apaydin ES, Shabahang S, Torabinejad M (2004) Hard-tissue healing after application of fresh or set MTA as root-end-filling material. J Endod 30,21-24

8. Shipper G, Grossman ES, Botha AJ, Cleaton-Jones PE (2004) Marginal adaptation of mineral trioxide aggregate (MTA) compared with amalgam as a root-end filling material: a low-vacuum (LV) versus high-vacuum (HV) SEM study. Int Endod J 37, 325-336

9. Yaltirik M, Ozbas H, Bilgic B, Issever H (2004) Reactions of connective tissue to mineral trioxide aggregate and amalgam. J Endod 30, 95-99

10. Grung B, Molven O, Halse A (1990) Periapical surgery in a Norwegian county hospital: follow-up findings of 477 teeth. J Endod 16, 411-417

11. Lustmann J, Friedman S, Shaharabany V (1991) Relation of pre- and intra-operative factors to prognosis of posterior apical surgery. J Endod 17, 239-241

12. Leonardo MR (2005) Semiologia e diagnóstico clínico/radiográfico das alterações patológicas pulpares. In Endodontia. Tratamento de canais radiculares: princípios técnicos e biológicos Vol 1, Leonardo MR ed, Artes Médicas, São Paulo, 21-48 (in Portuguese)

13. Testori T, Capelli M, Milani S, Weinstein RL (1999) Success and failure in periradicular surgery: a longitudinal retrospective analysis. Oral Surg Oral Med Oral Pathol Oral Radiol Endod 87, 493-498

14. Tanomaru Filho M, Luis MR, Leonardo MR, Tanomaru JM, Silva LA (2006) Evaluation of periapical repair following retrograde filling with different root-end filling materials in dog teeth with periapical lesions. Oral Surg Oral Med Oral Pathol
Oral Radiol Endod 102, 127-132

15. Navarre SW, Steiman HR (2002) Root-end fracture during retropreparation: a comparison between zirconium nitride-coated and stainless steel microsurgical ultrasonic instruments. J Endod 28, 330-332

16. Gogos C, Economides N, Stavrianos C, Kolokouris I, Kokorikos I (2004) Adhesion of a new methacrylate resin-based sealer to human dentin. $\mathrm{J}$ Endod 30, 238-240

17. Siqueira JF Jr, Roças IN, Abad EC, Castro AJ, Gahyva SM, Favieri A (2001) Ability of three rootend filling materials to prevent bacterial leakage. $\mathrm{J}$ Endod 27, 673-675

18. Soares J, Santos S, Silveira F, Nunes E (2007) Calcium hydroxide barrier over the apical root-end of a type III dens invaginatus after endodontic and surgical treatment. Int Endod J 40, 146-155

19. Holland R, Otoboni Filho JA, Bernabé PFE, Souza V, Nery MJ (1993) Healing process of dog's pulpless teeth after apicoectomy and root canal filling at different levels. Endod Dent Traumatol 9, 8-12

20. Sauveur G, Boccara E, Colon P, Sobel M, Boucher Y (1998) A photoelastimetric analysis of stress induced by root-end resection. J Endod 24, 740-743

21. Tidmarsh BG, Arrowsmith MG (1989) Dentinal tubules at the root ends of apicected teeth: a scanning electron microscopic study. Int Endod J 22, 184-189

22. Tronstad L, Andreasen JO, Hasselgren G, Kristerson L, Riis I (1981) pH changes in dental tissues after root canal filling with calcium hydroxide. J Endod $7,17-21$

23. Siqueira JF Jr, Lopes HP (1999) Mechanisms of antimicrobial activity of calcium hydroxide: a critical review. Int Endod J 32, 361-369

24. Soares JA, Santos KS. (2003) Apexification using calcium hydrozied associated with camphorated para-monoclorophenol - a clinical case report. J Bras Endod 4, 276-282 (in Portuguese)

25. Bernabé PFE, Holland R (1998) Use of calcium hydroxide in periapical surgery - biologocal and clinical considerations. Rev Assoc Paul Cir Dent 52, 460-465 (in Portuguese)

26. Soares JA. (2003) Microbiological, histopathological and histo-microbiological evaluation of premolar teeth from dogs following an induced chronic periapical lesion, after automatic biomechanical preparion and the application of a variety of dressings based on calcium hydroxide pastes. $\mathrm{PhD}$ thesis, Universidade Estadual Paulista, Araraquara, 394-428 (in Portuguese) 